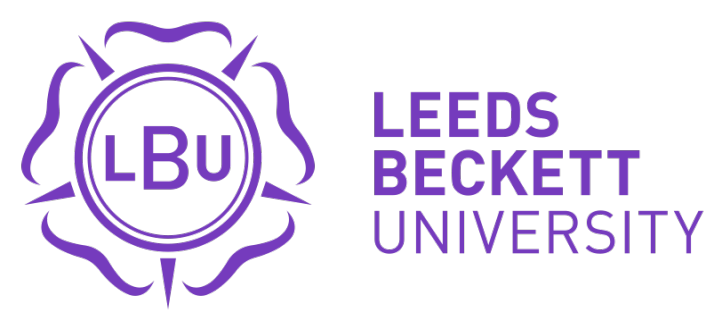

Citation:

Deighton, K and Barry, R and Connon, CE and Stensel, DJ (2013) Appetite, gut hormone and energy intake responses to low volume sprint interval and traditional endurance exercise. European journal of applied physiology, 113 (5). 1147 - 1156. ISSN 1439-6319 DOI: https://doi.org/10.1007/s00421012-2535-1

Link to Leeds Beckett Repository record:

https://eprints.leedsbeckett.ac.uk/id/eprint/210/

Document Version:

Article (Accepted Version)

The aim of the Leeds Beckett Repository is to provide open access to our research, as required by funder policies and permitted by publishers and copyright law.

The Leeds Beckett repository holds a wide range of publications, each of which has been checked for copyright and the relevant embargo period has been applied by the Research Services team.

We operate on a standard take-down policy. If you are the author or publisher of an output and you would like it removed from the repository, please contact us and we will investigate on a case-by-case basis.

Each thesis in the repository has been cleared where necessary by the author for third party copyright. If you would like a thesis to be removed from the repository or believe there is an issue with copyright, please contact us on openaccess@leedsbeckett.ac.uk and we will investigate on a case-by-case basis. 


\section{APPETITE, GUT HORMONE AND ENERGY INTAKE RESPONSES TO LOW VOLUME SPRINT INTERVAL AND TRADITIONAL ENDURANCE EXERCISE}

Kevin Deighton ${ }^{1}$, Ruth Barry ${ }^{1}$, Charlotte E. Connon ${ }^{1}$ and David J. Stensel ${ }^{1}$

${ }^{1}$ School of Sport, Exercise and Health Sciences, Loughborough University, Loughborough, United Kingdom

\section{Correspondence}

Dr David Stensel

School of Sport, Exercise and Health Sciences

Loughborough University,

Leicestershire

LE11 3TU

United Kingdom

Phone: $+44(0) 1509226344$

Fax: +44(0)1509226301

E-mail: D.J.Stensel@1boro.ac.uk 


\section{ABSTRACT}

Sprint interval exercise improves several health markers but the appetite and energy balance response is unknown. This study compared the effects of sprint interval and endurance exercise on appetite, energy intake and gut hormone responses. Twelve healthy males (mean(SD): age 23(3) years, body mass index 24.2(2.9) $\mathrm{kg} \cdot \mathrm{m}^{-2}$, maximum oxygen uptake 46.3(10.2) $\mathrm{mL} \cdot \mathrm{kg}^{-1} \cdot \mathrm{min}^{-1}$ ) completed three $8 \mathrm{~h}$ trials (control (CON), endurance exercise (END), sprint interval exercise (SIE)) separated by 1 week. Trials commenced upon completion of a standardised breakfast. Sixty minutes of cycling at $68.1(4.3) \%$ of maximum oxygen uptake was performed from $1.75-2.75 \mathrm{~h}$ in END. Six 30 s Wingate tests were performed from 2.25-2.75h in SIE. Appetite ratings, acylated ghrelin and peptide YY (PYY) concentrations were measured throughout each trial. Food intake was monitored from buffet meals at 3.5 and $7 \mathrm{~h}$ and an overnight food bag. Appetite $(\mathrm{P}<0.0005)$ and acylated ghrelin $(\mathrm{P}<0.002)$ were suppressed during exercise but more so during SIE. Peptide YY increased during exercise but most consistently during END $(\mathrm{P}<0.05)$. Acylated ghrelin was lowest in the afternoon of SIE $(\mathrm{P}=0.018)$ despite elevated appetite $(\mathrm{P}=0.052)$. Exercise energy expenditure was higher in END than SIE $(\mathrm{P}<0.0005)$. Energy intake was not different between trials $(\mathrm{P}>0.05)$. Therefore relative energy intake (energy intake minus the net energy expenditure of exercise) was lower in END than CON (15.7\%; $\mathrm{P}=0.006)$ and SIE (11.5\%; $\mathrm{P}=0.082$ ). An acute bout of endurance exercise resulted in lower appetite perceptions in the hours after exercise than sprint interval exercise and induced a greater $24 \mathrm{~h}$ energy deficit due to higher energy expenditure during exercise.

Key words: acylated ghrelin, peptide YY, appetite-regulating hormones, exercise-induced anorexia, compensation, energy balance 


\section{INTRODUCTION}

Within the last decade, an increasing number of studies have investigated the health and fitness implications of low volume, supramaximal sprint interval exercise. Despite substantially lower total work and energy expenditure, sprint interval exercise appears to elicit improvements in maximum oxygen uptake $\left(\mathrm{VO}_{2} \max \right)$, insulin sensitivity, postprandial lipaemia, and endothelial function that are comparable to those induced by traditional high volume prolonged endurance exercise (Babraj et al. 2009; Burgomaster et al. 2008; Freese et al. 2011; Rakobowchuk et al. 2008; Richards et al. 2010).

In the context of current society, where a 'lack of time' is commonly cited as a barrier to exercise (Trost et al. 2002), sprint interval exercise may offer a time-efficient method of inducing exercise-related health benefits. However, the weight loss response to low volume, sprint interval training remains equivocal (Babraj et al. 2009; Richards et al. 2010; Whyte et al. 2010) and is likely to be influenced by the extent of compensatory changes in appetite and energy intake after exercise (King et al. 2008).

Appetite and food intake are regulated at the physiological level by the neuroendocrine system, of which appetite-regulating gut hormones play a role as episodic mediators of hunger and satiety (Murphy and Bloom 2006). Ghrelin is the only known orexigenic gut peptide and is produced primarily by cells in the oxyntic glands of the stomach. Ghrelin is acylated via n-octanoylation of the serine 3 residue and although only $10-20 \%$ of ghrelin circulates in the acylated form, this is believed to be the form of ghrelin solely responsible for appetite stimulation (Ghigo et al. 2005).

Conversely, peptide YY (PYY) is an anorexigenic gut peptide, which is synthesised and released from L-cells predominantly located in the distal GI tract. Peptide YY circulates in the blood in two forms: the intact 36 amino acid peptide $\mathrm{PYY}_{1-36}$, and the truncated 34 amino 
acid peptide $\mathrm{PYY}_{3-36}$. Although both forms are present in the blood, $\mathrm{PYY}_{3-36}$ is more abundant and exerts more potent anorexigenic effects (Karra and Batterham 2010).

A consistent body of evidence indicates that plasma acylated ghrelin concentrations are acutely suppressed and PYY concentrations elevated, during and immediately after strenuous endurance exercise (Broom et al. 2009; King et al. 2011; Ueda et al. 2009). Such hormonal changes occur concomitantly with a decrease in appetite during exercise and have been postulated as a potential mechanism underlying exercise-induced appetite suppression (Broom et al. 2009). Furthermore, in contrast to energy restriction, energy deficits induced by exercise do not appear to elicit compensatory changes in appetite, energy intake, or circulating concentrations of acylated ghrelin and $\mathrm{PYY}_{3-36}$ in the hours after exercise (King et al. 2011).

The influence of exercise intensity on appetite and energy intake responses has received little attention and only a small range of submaximal intensities (35 to $75 \%$ of $\mathrm{VO}_{2}$ max) have been investigated, yielding equivocal findings. Thompson and colleagues (1988) demonstrated greater appetite suppression during exercise as intensity increased but no difference in energy intake after exercise, whereas Imbeault et al. (1997) found no differences in appetite but decreased energy intake as exercise intensity increased. Alternatively, Ueda and colleagues (2009) found no difference in the appetite or energy intake responses to different intensity exercise bouts. The effect of supramaximal exercise has not yet been investigated and may help to elucidate the importance of exercise intensity in determining the appetite, hormonal and energy intake responses to exercise.

The purpose of this study was to investigate the appetite, acylated ghrelin, total PYY and $24 \mathrm{~h}$ energy intake responses to $30 \mathrm{~min}$ of low volume sprint interval exercise compared with 60 min of traditional endurance exercise. We hypothesised that appetite and acylated ghrelin 
would be suppressed, and total PYY elevated, to a greater extent during sprint interval exercise than during endurance exercise, resulting in lower energy intake in the hours after sprint exercise.

\section{METHODS}

\section{Participants}

Following the approval of Loughborough University's Ethics Advisory Committee, twelve healthy males (19 - 29 years) gave their written informed consent to participate. Participants were non-smokers, not taking medication, weight stable for at least 6 months before the study and were not dieting. Females were not recruited due to potential sex-related differences in appetite, gut hormone and energy intake responses to exercise (Hagobian and Braun 2010). The physical characteristics of participants (mean (SD)) were as follows: age 23 (3) years, body mass index (BMI) 24.2 (2.9) kg.m ${ }^{-2}$, body mass 78.1 (9.6) kg, body fat 14.4 (4.7) \%, waist circumference $81.6(7.6) \mathrm{cm}$, maximum oxygen uptake $46.3(10.2) \mathrm{mL} \cdot \mathrm{kg}^{-1} \cdot \mathrm{min}^{-1}$.

\section{Participant Screening}

Prior to main trials participants visited the laboratory to undergo screening, familiarization and preliminary anthropometric measurements. Height and body weight were measured and body mass index subsequently calculated. Body fat percentage was estimated via skinfold measurements (Durnin and Womersley 1974) and waist circumference determined as the narrowest part of the torso between the xiphoid process and the iliac crest. A food preference questionnaire was completed to ensure acceptability of all food items available during the main trials. 


\section{Maximum Oxygen Uptake Test}

After familiarisation with the testing equipment, participants completed a continuous incremental exercise test on an electromagnetically braked cycle ergometer (Lode Excalibur Sport V2, Groningen, Netherlands) to volitional exhaustion to determine $\mathrm{VO}_{2}$ max. Participants began cycling at a work rate of $95 \mathrm{~W}$, with increments of $35 \mathrm{~W}$ every 3 min until volitional fatigue. Samples of expired gas were collected into Douglas bags during the third minute of each work rate increment and the final minute of the exercise test for the determination of oxygen uptake. The criteria for attainment of $\mathrm{VO}_{2} \max$ was to fulfil $\geq 3$ of the following criteria: 1) plateau of oxygen consumption despite increasing workload, 2) respiratory exchange ratio $>1.1,3$ ) heart rate within 10 beats. $\min ^{-1}$ of age-predicted maximum, and 4) rating of perceived exertion (RPE) $>18$ on the Borg scale (Borg 1973).

\section{Experimental Protocol}

Participants performed three main trials (control, continuous endurance exercise and sprint interval exercise) separated by one week in a counterbalanced Latin Square design. Participants completed a weighed food diary in the $24 \mathrm{~h}$ before the first main trial and replicated this before each subsequent trial. Alcohol, caffeine and strenuous physical activity were not permitted during this period. Participants arrived at the laboratory at 8.45 am after an overnight fast of at least $10 \mathrm{~h}$ and exerted themselves minimally when travelling to the laboratory, using motorized transport when possible.

Upon arrival to the laboratory, participants completed a baseline appetite questionnaire and then consumed a standardised breakfast meal within $15 \mathrm{~min}$. The $8 \mathrm{~h}$ trial commenced upon completion of the meal. Sixty min of continuous endurance exercise was performed in the endurance exercise trial (END) from $1.75-2.75 \mathrm{~h}$, whereas 30 min of supramaximal sprint interval exercise was performed in the sprint interval exercise trial (SIE) from $2.25-2.75 \mathrm{~h}$. 
No exercise was performed in the control trial (CON). Participants rested within the laboratory for the remainder of the day in all trials (sitting reading, working at a desk or watching television).

During each trial, appetite perceptions (hunger, satisfaction, fullness and prospective food consumption (PFC)) (Flint et al. 2000) were assessed at baseline, 0.25, 1.75, 2.25, 2.5, 2.75, 3 $\mathrm{h}$ and every $30 \mathrm{~min}$ thereafter using $100 \mathrm{~mm}$ visual analogue scales. Expired gas was collected into Douglas bags for 5 min after 5 min rest in a semi-supine position at: 4.5, 5.5, 7 and $8 \mathrm{~h}$ for determination of resting energy expenditure and substrate oxidation (Frayn 1983). Water was available ad libitum throughout each trial.

\section{Endurance Exercise Session}

Participants performed $60 \mathrm{~min}$ of continuous cycling exercise on an electromagnetically braked cycle ergometer (Lode Excalibur Sport V2, Groningen, Netherlands) at a work rate predicted to elicit $65 \%$ of $\mathrm{VO}_{2}$ max. Samples of expired gas were collected at 10, 20, 30, 45 and 60 min during exercise to monitor the intensity of the cycle, with adjustments made to the work rate if necessary. Heart rate and RPE were also assessed at these times. Energy expenditure of the session was calculated using the equation of Frayn (1983).

\section{Sprint Interval Exercise Session}

The sprint interval exercise session was modelled on recent studies conducted by Burgomaster and colleagues $(2007 ; 2008)$. After a 3.5 min warm up at a fixed power output of $30 \mathrm{~W}$, participants performed six $30 \mathrm{~s}$ sprints on an electronically braked cycle ergometer (Lode Excalibur Sport 925900, Groningen, Netherlands) against a resistance equivalent to $7.5 \%$ of body mass. Participants were instructed to begin pedalling as fast as possible $\sim 2 \mathrm{~s}$ before the appropriate load was applied by a computer interfaced with the ergometer and 
loaded with the appropriate software (Lode Ergometry Manager Wingate Test Plus). Participants were instructed to reach maximum fatigue by the end of the session and were verbally encouraged throughout. Peak power, mean power and fatigue index were subsequently determined using an online data acquisition system. Sprints were separated by 4 min recovery periods during which participants remained on the bike and cycled at a power output of $30 \mathrm{~W}$. A $3.5 \mathrm{~min}$ warm-down at a fixed resistance of $30 \mathrm{~W}$ concluded the session. Collection of expired gas during exercise was rendered impractical due to the high levels of nausea experienced by participants. Therefore, energy expenditure was estimated using the methods of Medbø et al. (1988). Individual regression equations were developed for each participant from the work rate/energy expenditure relationship during the maximum oxygen uptake test and used to estimate the energy expenditure of the average work rate of the 30 min session, thereby attempting to account for warm up, warm down, sprint and recovery periods. This method has been validated to provide a reliable relationship between work rate and energy expenditure (Medbø et al. 1988) and as an estimate of the energy cost of supramaximal exercise (Scott et al. 1991). Heart rate and RPE were recorded upon completion of each sprint.

\section{Net Energy Expenditure of Exercise}

To estimate the net energy expenditure of exercise (gross energy expenditure of exercise minus energy expenditure during the control trial), expired gas was collected into Douglas bags for 5 min every 15 min between 1.75 and $2.75 \mathrm{~h}$ during the control trial and energy expenditure subsequently calculated using the equation of Frayn (1983).

\section{Standardised breakfast, ad libitum buffet meals and overnight food bag}

Participants were provided with a standardised breakfast upon their arrival to the laboratory, which consisted of toasted white wheatgerm bread, margarine, strawberry jam, banana and 
orange juice. The macronutrient content of the meal was $72.9 \%$ carbohydrate, $9.5 \%$ protein and $17.6 \%$ fat. The breakfast provided $30 \%$ of the estimated daily energy needs for each individual for a sedentary day. To calculate this, resting daily energy requirements were estimated for each individual (Mifflin et al. 1990). This value was then multiplied by a physical activity level of 1.4 to represent a sedentary day.

Participants were given $30 \mathrm{~min}$ ad libitum access to a cold buffet meal at $3.5 \mathrm{~h}$ and a hot buffet meal at $7 \mathrm{~h}$. The items available at the cold buffet were: orange juice, semi-skimmed milk, three varieties of cereal, white bread, brown bread, butter, margarine, mayonnaise, cheese, ham, tuna, crisps, chocolate bars, cereal bars, cookies, muffins, apples, oranges and bananas. The items available at the hot buffet were: pasta, tomato pasta sauce, chicken pieces, cheese, white bread, brown bread, yoghurts, jelly, rice pudding, orange juice and semiskimmed milk. The buffet foods were presented identically on each trial and provided diversity in protein, fat and carbohydrate content. Food was presented in excess of expected consumption and participants were told to eat until 'comfortably full' and that additional food was available if desired. Participants consumed meals in isolation so that social influence did not affect food selection. Leftovers were weighed and food consumption was determined as the weighted difference of buffet items before and after each meal. The energy and macronutrient content of the items consumed was ascertained using manufacturers' values.

At the end of each trial, participants were free to select any of the items presented at the buffet meals to be included in an overnight food bag. Leftovers were returned the next day to determine the weighted difference in food items and subsequently energy intake.

\section{Blood Sampling}

During CON and END all venous blood was collected via a cannula (Venflon, Becton Dickinson, Helsinborg, Sweden), which was inserted into an antecubital vein at $1 \mathrm{~h}$. To 
minimise arm discomfort during the sprint exercise, the first 3 blood samples were collected via venepuncture and a cannula was then inserted at $3.25 \mathrm{~h}$, from which the remaining blood samples were collected. Venous blood samples were taken into pre-chilled 9-mL and 4.9-mL EDTA monovettes (Sarstedt, Leicester, UK) at 1.75, 2.47, 2.75, 3.5, 4.5, 5.5, 7 and $8 \mathrm{~h}$ for the measurement of plasma total PYY and acylated ghrelin, respectively. All samples were collected in the semi-supine position except for the $2.47 \mathrm{~h}$ sample during exercise, which was taken while participants remained seated on the bike. The 9-mL EDTA monovettes were spun at $856 \times g$ for $10 \mathrm{~min}$ at $4{ }^{\circ} \mathrm{C}$ (Heraeus Labofuge $400 \mathrm{R}$, Thermo Electron, Osterode, Germany) and the plasma supernatant aliquoted into 2-mL Eppendorf tubes prior to storage at $-20^{\circ} \mathrm{C}$ for later analysis. To prevent the degradation of acylated ghrelin, a $50 \mu \mathrm{L}$ solution containing potassium phosphate buffer (PBS), P-hydroxymercuribenzoic acid (PHMB) and sodium hydroxide $(\mathrm{NaOH})$ was added to the 4.9-mL EDTA monovettes. These 4.9-mL monovettes were spun at $1165 \times g$ for $10 \mathrm{~min}$ at $4{ }^{\circ} \mathrm{C}$. The plasma supernatant was then dispensed into a storage tube and $100 \mu \mathrm{L}$ of $1 \mathrm{M}$ hydrochloric acid was added per millilitre of plasma to preserve acylated ghrelin (Hosoda et al. 2004). Thereafter, samples were spun at $1165 \times g$ for 5 min at $4{ }^{\circ} \mathrm{C}$ prior to storage at $-20^{\circ} \mathrm{C}$.

\section{Biochemical Analysis}

Commercially available enzyme immunoassays were used to determine plasma concentrations of acylated ghrelin (SPI BIO, Montigny le Bretonneux, France) and total PYY (Millipore, Billerica, U.S.A.). To eliminate inter-assay variation, samples from each participant were analyzed in the same run. The within batch coefficient of variation for the assays were $5.7 \%$ and $4.2 \%$ for acylated ghrelin and total PYY, respectively. 


\section{Statistical Analysis}

Data was analysed using Predictive Analytics Software version 18.0 for Windows (SPSS Inc., Somers, NY, U.S.A.). All area under the curve (AUC) calculations were performed using the trapezoidal method. Exercise responses in END and SIE were compared using Students paired t-tests. One-way repeated measures ANOVA was used to assess trial-based differences in total energy/macronutrient intake as well as baseline and AUC values for appetite, acylated ghrelin and total PYY. Repeated measures, two-factor ANOVA was used to examine differences between trials over time for appetite, acylated ghrelin, total PYY and energy/macronutrient intake. Where significant main and interaction effects were found, posthoc analysis was performed using Holm-Bonferroni correction for multiple comparisons. Statistical significance for this study was accepted as $\mathrm{P}<0.05$. Results in text and tables are presented as mean (SD). Graphical representations of results are presented as mean (SEM) to avoid distortion of the graphs.

\section{RESULTS}

\section{Exercise Responses}

During END, participants completed the 60 min cycle at 154 (34) W. This elicited a mean oxygen consumption equivalent to 68.1 (4.3) $\%$ of $\mathrm{VO}_{2}$ max and a mean non-protein respiratory exchange ratio of $0.97(0.04)$, which reflected a proportional contribution to energy provision of 91 (16) \% carbohydrate and 9 (16) \% fat. During SIE, participants completed the six sprint intervals at a work rate of 537 (66) W, which resulted in a mean work rate of 79 (7) $\mathrm{W}$ for the 30 min session including warm up, warm down and recovery periods. 
Heart rate and RPE were significantly higher during sprint exercise than endurance exercise (heart rate 167 (10) vs. 153 (13) beats. $\mathrm{min}^{-1}$; RPE 18 (1) vs. 14 (1) for SIE and END, respectively; both $\mathrm{P}<0.01$ ). External work completed and net energy expenditure of exercise were significantly higher in END than SIE (external work 556 (121) vs. 143 (13) kJ; net energy expenditure 2640 (418) vs. 594 (50) kJ; both $\mathrm{P}<0.0005)$.

\section{Appetite}

Fasting appetite perceptions did not differ between trials at baseline (hunger $(\mathrm{P}=0.465)$, satisfaction $(\mathrm{P}=0.558)$, fullness $(\mathrm{P}=0.520)$ and PFC $(\mathrm{P}=0.567))$. Two-factor ANOVA revealed a main effect of time (all $\mathrm{P}<0.0005)$ and a trial $\mathrm{x}$ time interaction (all $\mathrm{P}<0.0005)$ for each appetite perception (Fig. 1). Post-hoc analysis of trial $\mathrm{x}$ time interactions demonstrated suppressed appetite immediately upon cessation of the sprint exercise but elevated appetite during the afternoon of the sprint exercise trial (see Fig. 1). There was also a trend towards a main effect of trial for hunger $(\mathrm{P}=0.084)$ indicating higher hunger perceptions in SIE than END.

Table 1 shows the AUC values for each appetite perception. One-way ANOVA revealed trends for a main effect of trial for hunger $(\mathrm{P}=0.089)$ and PFC $(\mathrm{P}=0.052)$ from $3.5-8 \mathrm{~h}$, indicating greater appetite during the afternoon of SIE than CON and END. A trend towards a main effect of trial was also present for total $8 \mathrm{~h}$ hunger AUC $(\mathrm{P}=0.079)$ indicating elevated hunger perceptions in SIE than END.

\section{Energy and macronutrient intake}

Two-factor ANOVA revealed a main effect of time for energy intake (Table 2) and macronutrient intake (Table 3; both $\mathrm{P}<0.0005)$ but no trial or interaction effects. 


\section{Relative energy intake}

One-way ANOVA revealed a significant main effect of trial for relative energy intake (REI) (energy intake minus the net energy expenditure of exercise), demonstrating lower REI in END than CON $(15.7 \% ; \mathrm{P}=0.006)$ and a tendency towards lower REI in END than SIE $(11.5 \% ; \mathrm{P}=0.082)$ but no difference in REI between SIE and CON $(\mathrm{P}=0.221$; Con 12,941 (3113); END 10,908 (3238); SIE 12,326 (2987) kJ). Closer inspection of the data revealed that 11 out of 12 participants had a lower REI in END than CON but only 6 out of 12 participants had a lower REI in SIE than CON. Nine out of 12 participants had a lower REI in END than SIE.

\section{Plasma acylated ghrelin and total PYY concentrations}

Initial plasma acylated ghrelin concentrations did not differ between trials $(\mathrm{P}=0.569)$. Twofactor ANOVA revealed a significant trial $(\mathrm{P}<0.0005)$, time $(\mathrm{P}=0.001)$ and trial $\mathrm{x}$ time interaction effect $(\mathrm{P}<0.0005)$ for plasma acylated ghrelin (Fig. 2). Post-hoc analysis of between trial differences revealed higher plasma acylated ghrelin concentrations in CON than END $(\mathrm{P}=0.024)$ and SIE $(\mathrm{P}<0.0005)$. Post-hoc analysis of trial $\mathrm{x}$ time interactions demonstrated suppressed acylated ghrelin immediately and $0.75 \mathrm{~h}$ after exercise in SIE relative to $\mathrm{CON}($ all $\mathrm{P}<0.002)$.

Area under the acylated ghrelin versus time curve was significantly lower in END and SIE than CON from $1.75-3.5 \mathrm{~h}$ and $1.75-8 \mathrm{~h}($ all $\mathrm{P}<0.05)$. Values were also lower in SIE than CON from $3.5-8 \mathrm{~h}(\mathrm{P}<0.0005)$.

Initial plasma total PYY concentrations did not differ between trials $(\mathrm{P}=0.255)$. Two-factor ANOVA revealed a significant time $(\mathrm{P}<0.0005)$ and trial $\mathrm{x}$ time interaction effect $(\mathrm{P}=0.001)$ for plasma total PYY concentrations (Fig. 3). Post-hoc analysis of trial $\mathrm{x}$ time interactions 
indicated elevated total PYY immediately after exercise in END and SIE relative to CON (both $\mathrm{P}<0.01$ ). However, after Holm-Bonferonni adjustment only END remained significantly higher than $\mathrm{CON}(\mathrm{P}<0.05)$, due to greater individual variability in the total PYY response to SIE. One-way ANOVA revealed a tendency for higher total PYY AUC in END and SIE than CON from $1.75-3.5 \mathrm{~h}(\mathrm{P}=0.068)$ but there was no difference between trials for $3.5-8 \mathrm{~h}(\mathrm{P}=0.369)$ and $1.75-8 \mathrm{~h}(\mathrm{P}=0.201)$.

\section{Resting energy expenditure and substrate utilisation}

Two-factor ANOVA revealed a main effect of time for resting energy expenditure and respiratory exchange ratio during the afternoon of the trials (both $\mathrm{P}<0.0005$ ) but no trial or interaction effects (Fig. 4).

\section{Correlations}

Plasma acylated ghrelin concentration was positively related to appetite at $5.5 \mathrm{~h}$ on END but negatively related to appetite at $3.5 \mathrm{~h}$ on $\operatorname{SIE}(\mathrm{P}<0.05)$. There was no correlation between plasma acylated ghrelin concentration immediately prior to ad libitum meals and subsequent energy consumption. Similarly, the percentage change in plasma acylated ghrelin after a meal was not related to energy intake at that meal.

Plasma total PYY concentration was negatively correlated with appetite at $1.75 \mathrm{~h}$ during $\mathrm{CON}$ and at 2.47, 2.75 and $3.5 \mathrm{~h}$ during END (all $\mathrm{P}<0.05$ ). The percentage increase in total PYY after ad libitum buffet meals was weakly but significantly positively correlated with energy intake during the meals $(\mathrm{r}=0.279, \mathrm{P}=0.017)$.

\section{DISCUSSION}

The purpose of this investigation was to compare the effect of low volume, supramaximal sprint interval exercise and continuous endurance exercise on appetite, acylated ghrelin, total 
PYY and energy intake responses. The primary findings are that sprint interval exercise induced a greater suppression of appetite and plasma acylated ghrelin concentrations during exercise but resulted in compensatory increases in appetite (though not food intake) in the hours after exercise. Furthermore, continuous endurance exercise induced a substantial $24 \mathrm{~h}$ energy deficit relative to the control and sprint trials, due to the high level of energy expenditure during the exercise bout.

In accordance with previous research, there was a marked decrease in appetite during both exercise bouts, which coincided with a decrease in plasma acylated ghrelin and an increase in plasma PYY concentrations (Broom et al. 2009; King et al. 2011; Ueda et al. 2009). The decreases in appetite and acylated ghrelin both occurred to a greater extent during sprint exercise, which strengthens the association between exercise-induced suppressions of these variables. However, despite greater appetite suppression during sprint exercise, endurance exercise stimulated more consistent increases in plasma total PYY concentrations. Such confliction would suggest that decreases in appetite during exercise are not dependent on changes in circulating concentrations of total PYY and that such changes are likely to be influenced by exercise mode and duration as well as intensity.

Despite simultaneous appetite and acylated ghrelin suppression during exercise, appetite perceptions returned to similar values between all trials immediately prior to the first buffet meal, yet acylated ghrelin remained significantly suppressed in the sprint trial, resulting in a negative correlation between these variables. Additionally, appetite was highest and acylated ghrelin concentrations lowest in the afternoon of the sprint trial. Such divergence between appetite and acylated ghrelin concentrations may question the role of exercise-induced decreases in acylated ghrelin as a determinant of appetite, despite simultaneous suppression during the exercise bout. 
Although increases in circulating ghrelin concentrations have been shown to increase appetite and energy intake in humans (Ghigo et al. 2005), the influence of physiological decreases in circulating ghrelin are less clear. Callahan and colleagues (2004) previously demonstrated that plasma ghrelin concentrations were depressed to a greater extent after higher caloric preloads but that the recovery of plasma ghrelin concentrations did not predict subsequent meal initiation. Furthermore, circulating ghrelin concentrations have been found to be inversely related to BMI and depressed in obese individuals (Tschöp et al. 2001). However, such changes in ghrelin do not appear to reduce appetite or aid weight loss in the obese (Cummings et al. 2002). It must be noted that ghrelin is only one component of the appetiteregulating neuroendocrine system and that appetite is likely to reflect many hormonal and psychological factors (King et al. 2007; Murphy and Bloom 2006). Nevertheless, the present study adds to the debate surrounding the importance of physiological decreases in acylated ghrelin as a determinant of appetite. This issue is likely to be clarified only when specific ghrelin antagonists become available for use in clinical investigations.

Despite substantial changes in appetite and acylated ghrelin and total PYY concentrations, energy and macronutrient intake did not differ between trials at any of the three feeding opportunities. This supports previous evidence that exercise does not provoke short-term compensatory increases in energy intake and suggests that the behavioural act of food intake may largely be governed by environmental contingencies and short-term postingestive physiological responses (Blundell and King 1999). Similar absolute food intake between trials resulted in a substantial negative energy balance in the endurance trial compared with the sprint and control trials due to the high level of energy expenditure during the endurance exercise bout $(\sim 2640 \mathrm{~kJ})$. It is unknown whether compensatory increases in energy intake occur in the longer term but it appears that prolonged endurance exercise is more beneficial for inducing a negative $24 \mathrm{~h}$ energy balance than low volume, sprint interval exercise. The 
practicalities of recommending multiple Wingate tests as a physical activity initiative for the general population must also be questioned as sprint interval exercise in the present study stimulated feelings of nausea in 11 out of 12 participants and induced vomiting in 3 participants.

One limitation of the present study is that energy expenditure of the sprint exercise was estimated rather than measured directly. Although it is possible that this may have underestimated the energy cost of exercise, numerous studies have acknowledged that sprint interval exercise expends substantially lower amounts of energy than prolonged endurance exercise (Babraj et al. 2009; Freese et al. 2011; Richards et al. 2010; Whyte et al. 2010). Furthermore, the estimated net energy cost of the sprint interval exercise in this study was slightly higher than previous estimates of gross energy expenditure (Babraj et al. 2009; Whyte et al. 2010). The methods employed in the present study attempted to account for the oxygen deficit of the sprints (Medbø et al. 1988; Scott et al. 1991), which is thought to be the primary determinant of elevations in energy expenditure during the recovery periods (Hagberg et al. 1980). However, it remains plausible that energy expenditure may have been underestimated as we did not account for other factors such as elevated body temperature, circulation and ventilation during recovery periods (Børsheim and Bahr 2003) or due to less efficient cycling at supramaximal workloads (Hunter et al. 1998). Such factors are likely to be trivial in comparison to the vast differences in exercise volume and work completed between exercise protocols but nonetheless must be acknowledged.

Boutcher (2011) recently speculated that high intensity intermittent exercise may be more beneficial for weight loss than continuous moderate intensity exercise due to greater postexercise decreases in appetite and increases in resting energy expenditure and fat oxidation. However, the present study provides evidence that appetite is higher in the hours after sprint interval exercise than continuous endurance exercise, despite greater appetite suppression 
during the sprint interval exercise. Furthermore, we did not detect any between trial differences in resting energy expenditure or substrate oxidation $1.75-5.25 \mathrm{~h}$ after exercise. Although it would have been preferable to collect such data using the ventilated hood system, the Douglas bag method employed in this study was sufficiently sensitive to detect mealrelated changes in resting energy expenditure of $\sim 0.5 \mathrm{~kJ} \cdot \mathrm{min}^{-1}$ and respiratory exchange ratio values of $\sim 0.03$. We are therefore confident that any meaningful differences in resting metabolism as a result of exercise would have been detected.

To the authors' knowledge only two studies have previously compared the resting metabolic responses to supramaximal interval exercise and moderately-strenuous endurance exercise (Bahr 1992; Laforgia et al. 1997). Of these studies, only one demonstrated a significant difference in resting metabolism between protocols but deemed that the $135 \mathrm{~kJ}$ higher energy expenditure in the $9 \mathrm{~h}$ after supramaximal exercise was of 'negligible physiological significance' for energy balance (Laforgia et al. 1997). Such findings have led some recent authors to conclude that to induce a negative energy balance, exercisers should focus on maximising energy expenditure during the exercise bout itself (Laforgia et al. 2006; Warren et al. 2009). This contention is supported by the finding of the present study that energy intake is unresponsive to substantial differences in exercise volume and intensity. Longer duration high intensity exercise may represent a more successful approach to inducing energy deficits than supramaximal sprint interval exercise as a result of higher exercise volume, external work and energy expenditure. However, this has yet to be investigated.

The present study is limited as the population sample was comprised of young, healthy males; therefore the findings may not generalise to other populations such as the elderly or obese. Additionally, the physically demanding exercise protocols employed in this study would be unsuitable for clinical populations. Further work should be performed to investigate the effect of achievable exercise protocols on energy balance in overweight and obese populations in 
particular, as these are the populations where weight management strategies hold the most clinical relevance.

In conclusion, this is the first study to investigate appetite and energy intake responses to the recently popularised 'sprint interval training' protocol. Energy intake was unaffected by exercise, which resulted in a negative $24 \mathrm{~h}$ energy balance after traditional endurance exercise compared with sprint interval exercise, due to differences in energy expenditure. Furthermore, sprint exercise stimulated compensatory increases in appetite in the hours after exercise despite lower circulating acylated ghrelin concentrations. Future studies should be conducted to elucidate the influence of decreases in acylated ghrelin on appetite and to examine whether the differences in acute appetite and energy balance responses to these exercise protocols transpire into differences in weight loss if used as weight management interventions.

\section{ACKNOWLEDGEMENTS}

We would like to thank all of the volunteers for their participation in this study.

\section{CONFLICT OF INTEREST}

The authors declare that they have no conflict of interest. 


\section{REFERENCES}

Babraj JA, Vollaard NBJ, Keast C, Guppy FM, Cottrell G, Timmons JA (2009) Extremely short duration high intensity interval training substantially improves insulin action in young healthy males. BMC Endocr Disord 9: 3

Bahr R (1992) Excess postexercise oxygen consumption--magnitude, mechanisms and practical implications. Acta Physiol Scand Suppl 605: 1-70

Blundell JE, King NA (1999) Physical activity and regulation of food intake: current evidence. Med Sci Sports Exerc 31: S573-83

Borg GA (1973) Perceived exertion: a note on 'history' and methods. Med Sci Sports 5: 90-3

Børsheim E, Bahr R (2003) Effect of exercise intensity, duration and mode on post-exercise oxygen consumption. Sports Med 33: 1037-60

Boutcher SH (2011) High-intensity intermittent exercise and fat loss. J Obes 868305

Broom DR, Batterham RL, King JA, Stensel DJ (2009) Influence of resistance and aerobic exercise on hunger, circulating levels of acylated ghrelin, and peptide YY in healthy males. Am J Physiol Regul Integr Comp Physiol 296: R29-35

Burgomaster KA, Cermak NM, Phillips SM, Benton CR, Bonen A, Gibala MJ (2007) Divergent response of metabolite transport proteins in human skeletal muscle after sprint interval training and detraining. Am J Physiol Regul Integr Comp Physiol 292: R1970-6

Burgomaster KA, Howarth KR, Phillips SM, Rakobowchuk M, Macdonald MJ, McGee SL, Gibala MJ (2008) Similar metabolic adaptations during exercise after low volume sprint interval and traditional endurance training in humans. J Physiol 586: 151-60 
Callahan HS, Cummings DE, Pepe MS, Breen PA, Matthys CC, Weigle DS (2004)

Postprandial suppression of plasma ghrelin level is proportional to ingested caloric load but does not predict intermeal interval in humans. J Clin Endocrinol Metab 89: 1319-1324

Cummings DE, Weigle DS, Frayo RS, Breen PA, Ma MK, Dellinger EP, Purnell JQ (2002) Plasma ghrelin levels after diet-induced weight loss or gastric bypass surgery. N Engl J Med 346: $1623-30$

Durnin JV, Womersley J (1974) Body fat assessed from total body density and its estimation from skinfold thickness: measurements on 481 men and women aged from 16 to 72 years. $\mathrm{Br}$ J Nutr 32: 77-97

Flint A, Raben A, Blundell JE, Astrup A (2000) Reproducibility, power and validity of visual analogue scales in assessment of appetite sensations in single test meal studies. Int J Obes Relat Metab Disord 24: 38-48

Frayn KN (1983) Calculation of substrate oxidation rates in vivo from gaseous exchange. $\mathrm{J}$ Appl Physiol 55: 628-34

Freese EC, Levine AS, Chapman DP, Hausman DB, Cureton KJ (2011) Effects of acute sprint interval cycling and energy replacement on postprandial lipemia. J Appl Physiol 111: $1584-9$

Ghigo E, Broglio F, Arvat E, Maccario M, Papotti M, Muccioli G (2005) Ghrelin: more than a natural GH secretagogue and/or an orexigenic factor. Clin Endocrinol 62: 1-17

Hagberg JM, Mullin JP, Nagle FJ (1980) Effect of work intensity and duration on recovery O2. J Appl Physiol 48: 540-4 
Hagobian TA, Braun B (2010) Physical activity and hormonal regulation of appetite: sex differences and weight control. Exerc Sport Sci Rev 38: 25-30

Hosoda H, Doi K, Nagaya N, Okumura H, Nakagawa E, Enomoto M, Ono F, Kangawa K (2004) Optimum collection and storage conditions for ghrelin measurements: octanoyl modification of ghrelin is rapidly hydrolyzed to desacyl ghrelin in blood samples. Clin Chem 50: $1077-80$

Hunter GR, Weinsier RL, Bamman MM, Larson DE (1998) A role for high intensity exercise on energy balance and weight control. Int J Obes Relat Metab Disord 22: 489-93

Imbeault P, Saint-Pierre S, Alméras N, Tremblay A (1997) Acute effects of exercise on energy intake and feeding behaviour. Br J Nutr 77: 511-21

Karra E, Batterham RL (2010) The role of gut hormones in the regulation of body weight and energy homeostasis. Mol Cell Endocrinol 316: 120-8

King JA, Wasse LK, Ewens J, Crystallis K, Emmanuel J, Batterham RL, Stensel DJ (2011)

Differential acylated ghrelin, peptide YY3-36, appetite, and food intake responses to equivalent energy deficits created by exercise and food restriction. J Clin Endocrinol Metab 96: $1114-21$

King NA, Caudwell P, Hopkins M, Byrne NM, Colley R, Hills AP, Stubbs JR, Blundell JE (2007) Metabolic and behavioral compensatory responses to exercise interventions: barriers to weight loss. Obesity 15: 1373-83

King NA, Hopkins M, Caudwell P, Stubbs RJ, Blundell JE (2008) Individual variability following 12 weeks of supervised exercise: identification and characterization of compensation for exercise-induced weight loss. Int J Obes 32: 177-84 
Laforgia J, Withers RT, Gore CJ (2006) Effects of exercise intensity and duration on the excess post-exercise oxygen consumption. J Sports Sci 24: 1247-64

Laforgia J, Withers RT, Shipp NJ, Gore CJ (1997) Comparison of energy expenditure elevations after submaximal and supramaximal running. J Appl Physiol 82: 661-6

Medbø JI, Mohn AC, Tabata I, Bahr R, Vaage O, Sejersted OM (1988) Anaerobic capacity determined by maximal accumulated O2 deficit. J Appl Physiol 64: 50-60

Mifflin MD, St Jeor ST, Hill LA, Scott BJ, Daugherty SA, Koh YO (1990) A new predictive equation for resting energy expenditure in healthy individuals. Am J Clin Nutr 51: 241-7

Murphy KG, Bloom SR (2006) Gut hormones and the regulation of energy homeostasis. Nature 444: 854-9

Rakobowchuk M, Tanguay S, Burgomaster KA, Howarth KR, Gibala MJ, MacDonald MJ (2008) Sprint interval and traditional endurance training induce similar improvements in peripheral arterial stiffness and flow-mediated dilation in healthy humans. Am J Physiol Regul Integr Comp Physiol 295: R236-42

Richards JC, Johnson TK, Kuzma JN, Lonac MC, Schweder MM, Voyles WF, Bell C (2010) Short-term sprint interval training increases insulin sensitivity in healthy adults but does not affect the thermogenic response to beta-adrenergic stimulation. J Physiol 588: 2961-72

Scott CB, Roby FB, Lohman TG, Bunt JC (1991) The maximally accumulated oxygen deficit as an indicator of anaerobic capacity. Med Sci Sports Exerc 23: 618-24

Thompson DA, Wolfe LA, Eikelboom R (1988) Acute effects of exercise intensity on appetite in young men. Med Sci Sports Exerc 20: 222-7 
Trost SG, Owen N, Bauman AE, Sallis JF, Brown W (2002) Correlates of adults' participation in physical activity: review and update. Med Sci Sports Exerc 34: 1996-2001

Tschöp M, Weyer C, Tataranni PA, Devanarayan V, Ravussin E, Heiman ML (2001) Circulating ghrelin levels are decreased in human obesity. Diabetes 50: 707-9

Ueda SY, Yoshikawa T, Katsura Y, Usui T, Fujimoto S (2009) Comparable effects of moderate intensity exercise on changes in anorectic gut hormone levels and energy intake to high intensity exercise. J Endocrinol 203: 357-64

Warren A, Howden EJ, Williams AD, Fell JW, Johnson NA (2009) Postexercise fat oxidation: effect of exercise duration, intensity, and modality. Int J Sport Nutr Exerc Metab 19: $607-23$

Whyte LJ, Gill JMR, Cathcart AJ (2010) Effect of 2 weeks of sprint interval training on health-related outcomes in sedentary overweight/obese men. Metabolism 59: 1421-8 
Table 1 Area under the curve values for appetite perceptions in the control, endurance and sprint trials

\begin{tabular}{|c|c|c|c|}
\hline & $\begin{array}{c}\text { Morning } \\
\text { (0-3.5 h) } \\
\text { units } 3.5 \mathrm{~h}\end{array}$ & $\begin{array}{c}\text { Afternoon } \\
\text { (3.5-8 h) } \\
\text { units } 4.5 \mathrm{~h}\end{array}$ & $\begin{array}{c}\text { Total trial } \\
\text { (0-8 h) } \\
\text { units } 8 \mathrm{~h}\end{array}$ \\
\hline \multicolumn{4}{|l|}{ Hunger } \\
\hline Control & $116 \quad(45)$ & $106 \quad(53)$ & $222 \quad(71)$ \\
\hline Endurance & $93 \quad(56)$ & $100 \quad(36)$ & $193 \quad(79)$ \\
\hline Sprint & $101 \quad(59)$ & $130 \quad(44)$ & 231 \\
\hline \multicolumn{4}{|l|}{ Satisfaction } \\
\hline Control & $210 \quad(61)$ & $319 \quad(60)$ & $528 \quad(91)$ \\
\hline Endurance & $220 \quad(63)$ & $326 \quad(52)$ & $546 \quad(97)$ \\
\hline Sprint & $226 \quad(61)$ & $296 \quad(48)$ & $521 \quad(92)$ \\
\hline \multicolumn{4}{|l|}{ Fullness } \\
\hline Control & $200 \quad(64)$ & 319 (67) & 518 \\
\hline Endurance & $217 \quad(68)$ & 329 (46) & $546 \quad(96)$ \\
\hline Sprint & $227 \quad(63)$ & $297 \quad(46)$ & $523 \quad(95)$ \\
\hline \multicolumn{4}{|l|}{ PFC } \\
\hline Control & $132 \quad(58)$ & $118 \quad(56)$ & $250 \quad(86)$ \\
\hline Endurance & $112 \quad(62)$ & $105 \quad(42)$ & $217 \quad(91)$ \\
\hline Sprint & $105 \quad(63)$ & $144 \quad(48)$ & $250 \quad(101)$ \\
\hline
\end{tabular}

Values are mean $(\mathrm{SD}) . \mathrm{N}=12 . \mathrm{PFC}=$ prospective food consumption. Afternoon AUC for hunger and PFC tended to be highest in the sprint trial (One-way ANOVA: $\mathrm{P}=0.089$ and $\mathrm{P}=$ 0.052, respectively). Total $8 \mathrm{~h}$ AUC for hunger tended to be highest in the sprint trial (Oneway ANOVA: $\mathrm{P}=0.079)$ 
Table 2 Ad libitum energy intake during the control (CON), endurance (END) and sprint (SIE) trials

\begin{tabular}{lcclrlrl}
\hline & & \multicolumn{2}{c}{ CON } & \multicolumn{2}{c}{ END } & \multicolumn{2}{c}{ SIE } \\
\hline Buffet 1 (cold) & kJ & 5715 & $(1866)$ & 6121 & $(2000)$ & 5460 & $(1611)$ \\
Buffet 2 (hot) & kJ & 4632 & $(1075)$ & 5201 & $(1180)$ & 4749 & $(1146)$ \\
Overnight & kJ & 2594 & $(1172)$ & 2222 & $(1054)$ & 2711 & $(1372)$ \\
Total trial & kJ & 12,941 & $(3113)$ & 13,548 & $(3205)$ & 12,920 & $(2983)$ \\
\hline
\end{tabular}

Values are mean (SD). $\mathrm{N}=12$. No significant differences between trials 
Table 3 Macronutrient intake in the control (upper panel), endurance (middle panel) and sprint (lower panel) trials

\begin{tabular}{|c|c|c|c|c|}
\hline & & Fat & Carbohydrate & Protein \\
\hline \multicolumn{5}{|l|}{ Control } \\
\hline Buffet 1 & $\mathrm{~g}$ & $57.7(23.8)$ & $163.8(52.5)$ & $48.0(16.2)$ \\
\hline Buffet 2 & $\mathrm{~g}$ & $21.4(6.7)$ & $165.0(38.2)$ & $63.4(22.7)$ \\
\hline Overnight & $\mathrm{g}$ & $20.3(13.7)$ & 89.8 (33.6) & $19.6(12.7)$ \\
\hline Total & $\mathrm{g}$ & $99.4(33.2)$ & $418.6(95.7)$ & $131.0(34.7)$ \\
\hline \multicolumn{5}{|l|}{ Endurance } \\
\hline Buffet 1 & $\mathrm{~g}$ & $59.5(28.4)$ & $182.6(54.9)$ & $49.3(11.7)$ \\
\hline Buffet 2 & $\mathrm{~g}$ & $25.6(6.9)$ & $182.2(48.8)$ & $71.0(20.0)$ \\
\hline Overnight & $\mathrm{g}$ & $16.7(11.3)$ & $81.2(32.6)$ & $14.1(12.6)$ \\
\hline Total & $\mathrm{g}$ & $101.8(37.6)$ & $446.0(92.0)$ & $134.4(33.2)$ \\
\hline \multicolumn{5}{|l|}{ Sprint } \\
\hline Buffet 1 & $\mathrm{~g}$ & 50.7 (20.9) & $164.7(41.6)$ & $47.4(20.8)$ \\
\hline Buffet 2 & $\mathrm{~g}$ & $24.2(8.8)$ & $163.7(40.4)$ & $65.6(17.7)$ \\
\hline Overnight & $\mathrm{g}$ & $18.7(12.1)$ & $101.3(47.7)$ & $18.7(13.4)$ \\
\hline Total & $\mathrm{g}$ & $93.5(28.8)$ & $429.8(98.0)$ & $131.7(31.0)$ \\
\hline
\end{tabular}

Values are mean (SD). $\mathrm{N}=12$. No significant differences between trials 
Fig. 1 Perceptions of hunger (a), satisfaction (b), prospective food consumption (c) and fullness $(\mathrm{d})$ in $\operatorname{CON}(\boldsymbol{\nabla}), \operatorname{END}(\bullet)$ and SIE $(\circ)$ trials. Values are mean $(\mathrm{SEM}) . \mathrm{N}=12$. Lightly shaded rectangle indicates endurance exercise, black rectangle indicates sprint interval exercise, hatched shaded rectangle indicates standardised breakfast meal, horizontally shaded rectangle indicates cold buffet meal, vertically shaded rectangle indicates hot buffet meal. * Different between SIE and CON, ${ }^{\dagger}$ Different between SIE and END, P < 0.05

Fig. 2 Plasma concentrations of acylated ghrelin in $\operatorname{CON}(\boldsymbol{\nabla}), \operatorname{END}(\bullet)$ and $\operatorname{SIE}(\circ)$ trials. Values are mean $(\mathrm{SEM}) . \mathrm{N}=12$. Lightly shaded rectangle indicates endurance exercise, black rectangle indicates sprint interval exercise, horizontally shaded rectangle indicates cold buffet meal, vertically shaded rectangle indicates hot buffet meal. * Different between SIE and $\mathrm{CON}$

Fig. 3 Plasma concentrations of total PYY in CON ( $\nabla)$, END (•) and SIE (०) trials. Values are mean (SEM). $\mathrm{N}=12$. Lightly shaded rectangle indicates endurance exercise, black rectangle indicates sprint interval exercise, horizontally shaded rectangle indicates cold buffet meal, vertically shaded rectangle indicates hot buffet meal. ${ }^{*}$ Different between END and CON, $\mathrm{P}<0.05$

Fig. 4 Resting energy expenditure (a) and respiratory exchange ratio (b) in CON ( $\boldsymbol{\nabla}$ ), END $(\bullet)$ and SIE $(\circ)$ trials. Values are mean $(\mathrm{SEM}) . \mathrm{N}=12$. Vertically shaded rectangle indicates hot buffet meal 
Figure 1
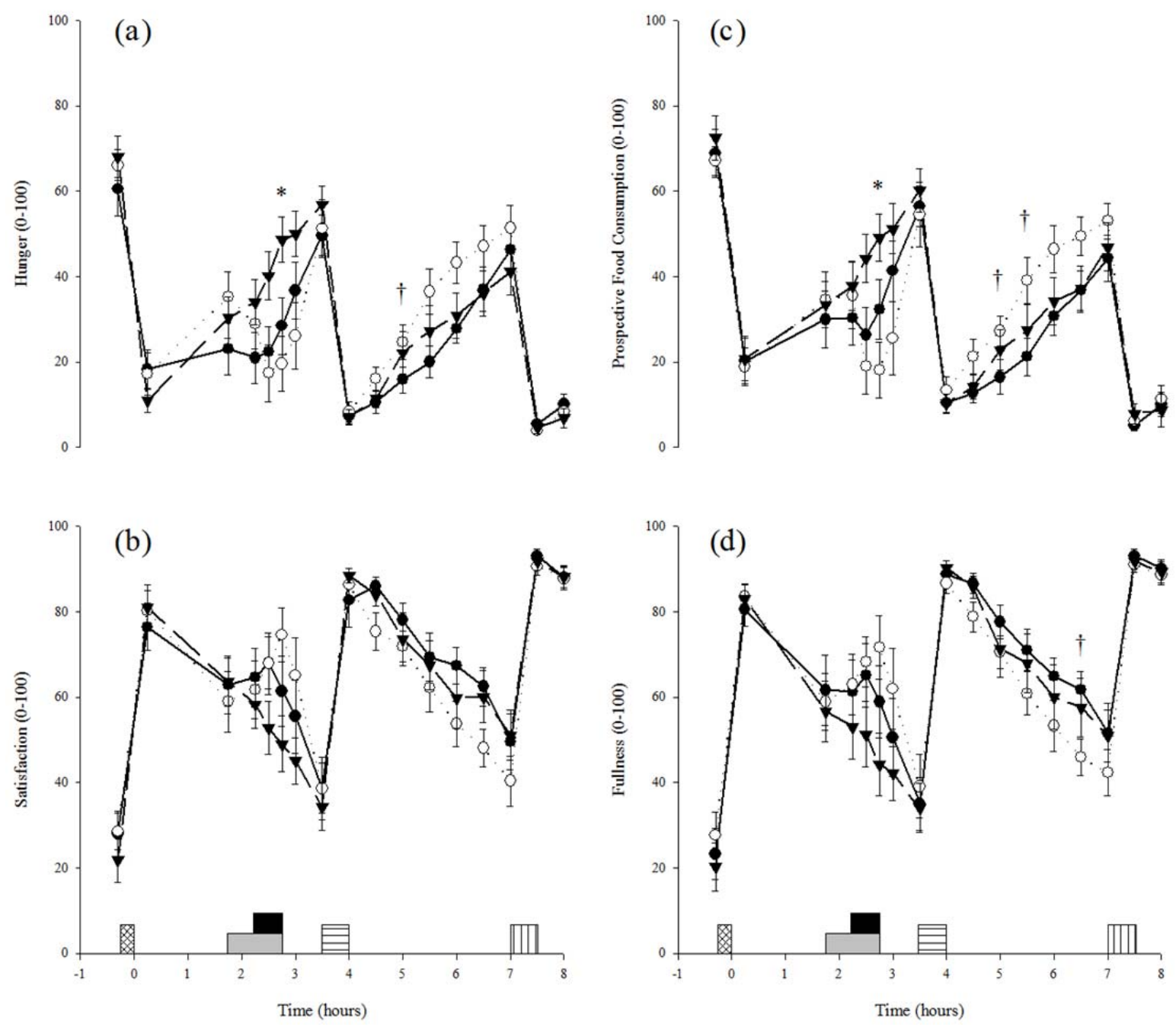
Figure 2

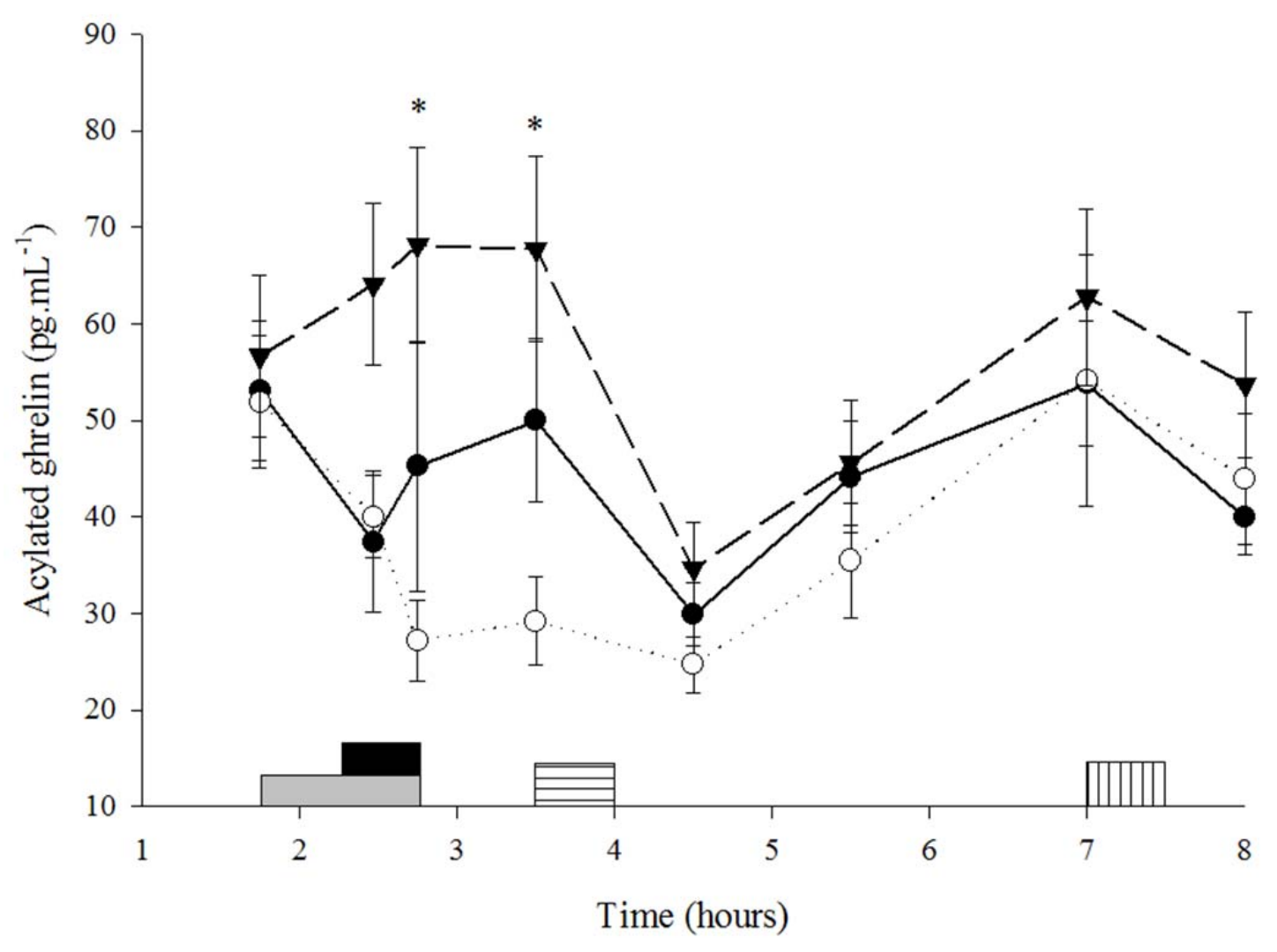


Figure 3

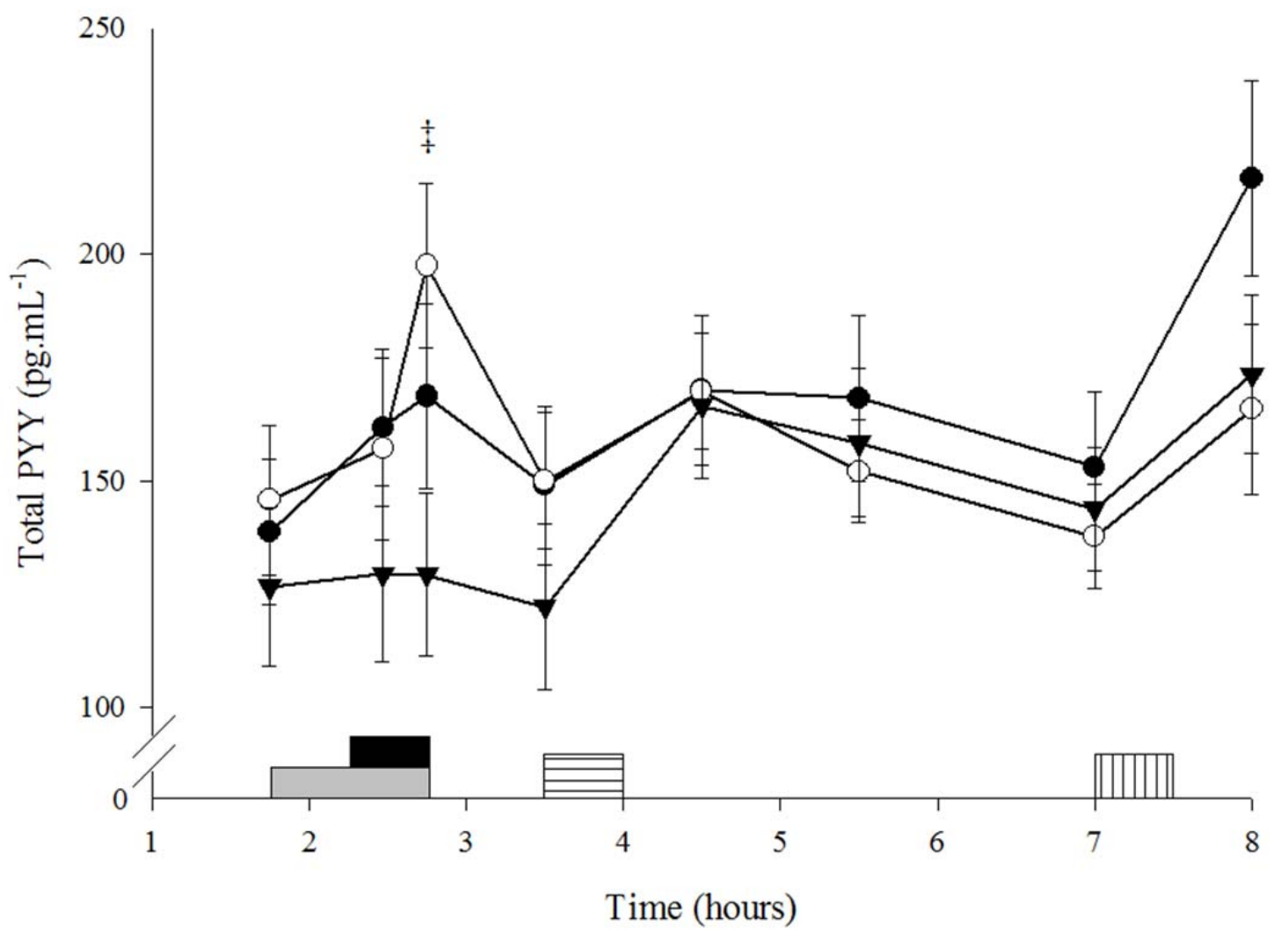


Figure 4
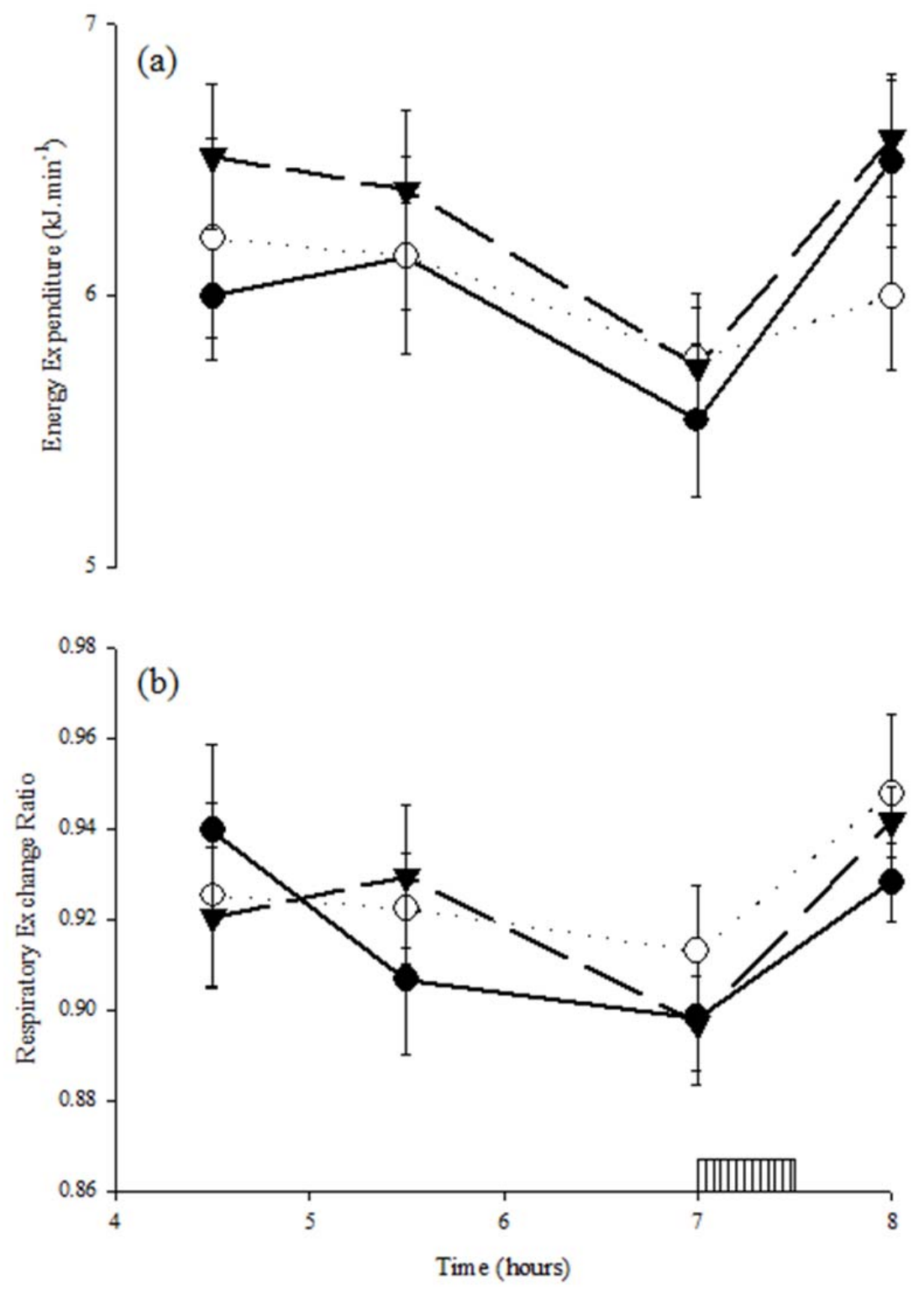